\title{
Are Accounting Standards Memes? The Survival of Accounting Evolution in an Age of Regulation
}

\author{
Brian A Rutherford ${ }^{1}$ (D) \\ Published online: 7 July 2020 \\ (C) The Author(s) 2020
}

\begin{abstract}
This paper employs memetics to argue against the view that standardisation overwhelms the evolution of accounting. I suggest that, in an unregulated setting, accounting procedures constitute classic memes and survive according to their fitness for their environment, which is predominantly a matter of their suitability for investment decision-making. In a standardising regime, the standardising canon embodies a special kind of meme encoding ideas as actions to be imitated to realise those ideas. Evolutionary pressures and the canon develop in tandem, although not necessarily synchronously.

If we accept the central tenet of memetics, which is also the assumption underlying the argument challenged here, that memes emerging before regulation were responsive to evolutionary pressures, we can analyse the responsiveness of the standardising canon by examining its relationship to a counterfactual continuation of the pre-regulated regime. The degree of synchronicity is an empirical, but elusive, question and we should follow Dennett's recommendation that we settle for the philosophical realisations we can glean from memetics.

I argue that three factors are of importance in addressing the question. Accounting memes function within a dense ecology, limiting radical and destabilising change. There has been a high degree of continuity, permeability and commonality in the intellection driving development: the same thinking has influenced policy design wherever it has taken place. Finally, the principal determinant of successful adaptation did not change on the transition to standardisation and the canon and its vehicles have survived. Consequently, we can conclude that standardisation has not disrupted the development of accounting.
\end{abstract}

Keywords Accounting standardisation - Accounting theory · Accounting practice $\cdot$ Evolution · Memetic theory

Brian A Rutherford

b.a.rutherford@kent.ac.uk

1 Kent Business School, University of Kent, Canterbury, Kent CT2 7FS, UK 


\section{Introduction}

Classical accounting theorists seeking to justify the attention they gave to accounting practice in their theorising often drew on evolutionary thought to defend the utility and progressiveness of principles for corporate reporting derived from practice: from a multitude of procedures, devised by discrete and independent accountants and tested by the financial community by trial and error over time, there will emerge as accepted policies those best suited to the requirements of the environment they face. The last half-century or so has seen, across much of the developed world, a shift in institutional arrangements for devising accounting policies, from choice exercised by individual practitioners, albeit latterly within a structure involving increasing levels of authoritative, but ultimately non-mandatory guidance and influence, to mandatory standardisation. Some modern commentators (see, for example, Basu 2015; Braun 2019; Sunder 2011), argue that standardisation introduces an impetus that is, from an evolutionary standpoint, arbitrary, so that it overwhelms the progressive force of adaptation by selection based on fitness for the environment. This conclusion appears to justify calls for a return to accounting's 'prelapsarian' age of innocence, unspoilt by regulation or, at least, a reversal of the current direction of travel; such calls have been made by, among others, Benston et al. (2006), Jamal and Sunder (2014), Myddelton (2004), Walker (2010) and West (2003). The argument thus has an important bearing on public debate about future arrangements for generating accounting policies and deserves serious attention.

In this paper, I want to argue the contrary case. Because it addresses the generation and development of ideas within an evolutionary framework, I shall employ Richard Dawkins' memetic theory to analyse the issues involved and offer, in Daniel Dennett's characterisation (see Dennett 1995 p 346), a philosophical realisation as to whether the change might be expected to have overwhelmed the evolution of accounting. ${ }^{1}$ Whether memetic theory can provide philosophical realisations is a matter of some controversy but distinguished philosophers can be found who hold that it can, including Professor Dennett himself.

Memes are ideas, transmitted culturally, which grow and prosper according to their strengths in the struggle for survival and not necessarily by the benefits they provide for their hosts. I argue that accounting procedures are memes that must struggle for survival in an environment shaped by the needs of financial statement users. In a standardising regime, standards embody a special kind of meme, encoding ideas in the form of actions to be imitated to realise the consequences of those ideas. The impact of standardisation, by comparison with a previously unregulated setting, can be examined by analysing the relationship between the conditions of production of accounting memes under the standardising regime and those under the counterfactual of a continuation of the unregulated setting.

I suggest that, in the face of a relatively high degree of stability in the order generating accounting policy memes, broadly defined, through time, including as the standardising emerges and itself evolves, it would be reasonable to expect that standardisation has not overwhelmed accounting evolution and I argue that we do observe such stability in the memetic ecology, in the intellection driving memetic development, and in the factors determining adaptive success.

My conclusion is a philosophical insight drawn from the nature of accounting policies and the speculation that the order generating those policies is sufficiently stable. It is not an

\footnotetext{
${ }^{1}$ The only previous literature applying memetic analysis to financial accounting of which I am aware is Ji and Lu's (2013) study of the evolution of bookkeeping methods in twentieth century China.
} 
empirical finding as such; indeed, an empirical result is strictly unachievable given that determining the accounting policies that would have evolved in the absence of a standardising regime requires counterfactual speculation. The philosophical insight I offer should, of course, achieve a degree of coherence with experience in the accounting world and I offer empirical evidence in this spirit. I argue that my conclusion justifies a measure of scepticism towards claims that accounting standardisation overwhelms accounting evolution and invites a search for other explanations of evidence suggesting that this may have occurred. I examine one such claim and offer an alternative explanation.

The remainder of the paper is organised as follows. I first set out briefly the classical theorists' position and the view of the commentators I am arguing against. I then describe memetic theory generally and explore the literature addressing the memetics of regulation in law and theology, drawing out the notion of a standardising canon embodying memes as ideas in the form of actions to be imitated. I go on to discuss the way accounting procedures, including accounting policies, function as memes in an unregulated setting and in a standardising canon. The following section addresses the central question of the impact of standardisation on the sensitivity of the development of accounting memes to the evolutionary pressures generated by the commercial and social environment of the discipline. I then examine some empirical evidence advanced for an adverse impact of standardisation, suggesting an alternative interpretation consistent with my argument. There is a brief concluding section.

\section{The Alleged Impact of Standardisation}

The position of classical accounting theorists described in the introduction drew, often explicitly, on American philosophical pragmatism and, in particular, the work of John Dewey, 'evolution's first philosopher' (Popp 2007 book title). Devine (1966), for example, points to pragmatist themes in Littleton's well-known Structure of accounting theory (1953 p 185), which puts the position in the following terms:

We know that accounting practices were developed and in use before theories appeared explaining the things done. Long ago the basic methods of double entry were worked out by trial and error. Slowly the practices became verbalized into rules guiding transaction analyses, posting, balancing and other operations.... Methods devised by many different people were used and tested by many others. Over the years, and by common consent after tested use, the most suitable procedures became generally accepted practices. Teachers ... of accounting ... found it necessary to supplement ... procedure by explanations and justifications.... Hence it is appropriate to say that both the methods of practice and the explanations of theory were inductively derived out of experience.

Other examples of the argument drawn from evolutionary pragmatism include Beams (1969), Deinzer (1965, 1966), Devine (1966, 1985, see Williams 2001 p 695), Dopuch (1962), Moonitz (1961; see Littleton 1962), Paton (1922; see Deinzer 1965; Devine 1966 p 190) and Paton and Littleton (1940; see Deinzer 1965 p 86).

An early exponent of the view that the developmental forces previously shaping practice to its environment would be disrupted, subverted, and eventually overwhelmed by the external, and inevitably, from an evolutionary standpoint, arbitrary, interventions of standard-setters, was Baxter (1981 p 7, see also Baxter 1953, 1982): 
[A] standards board ... weighs the pros and cons of different theories, and decides for us that one is the best. In short, authority here informs us where the truth lies. History suggests that authorities have in the past not been too successful at this task. The most eminent authorities erred persistently on, for instance, the shape of the earth, the origins of life, and the circulation of the blood .... We cannot with complete confidence expect infallibility in the future.

Among more recent commentators, the argument is advanced most forcefully by Basu ( $2015 \mathrm{p}$ 237):

I argue that the trial-and-error evolution of accounting over millennia led to better competitive performance for individuals and organisations, and that evolved accounting embeds several broad regularities that all accountants should learn as foundational concepts. Thus, pre-SEC [Securities and Exchange Commission] evolved accounting practice [ie. US practice before standardisation] followed (unrecognised) general scientific laws, although ideological standard setters have striven to replace them with their unscientific rules over the last half century.

The case is also made in one way or another in Basu et al. (2009), Basu and Waymire (2019), Braun (2019) and Sunder (2011).

\section{Memetic Theory}

Richard Dawkins introduced the concept of a meme ${ }^{2}$ in The Selfish Gene (1976), in an attempt to explain forms of human behaviour injurious to the spread of an individual's genes behaviour, that is, contradicting Dawkins' interpretation of Darwinian (biological) evolution. An example of such behaviour would be impoverishing oneself, and risking ill-health, in pursuit of art. Dawkins argued that the ideas behind human behaviour are themselves in competition with each other and subject to a process analogous to the natural selection that determines biological evolution: a meme, or unit of cultural transmission, will prosper and spread if it possesses attributes which give it advantages over other memes in the struggle for survival, and may do so regardless of any benefits or disbenefits it yields for its hosts. Thus the appeal of achieving artistic greatness drives individuals to forego material well-being, including opportunities to reproduce.

Contemporary memetic theory (Blackmore 1999 p 10; Dennett 1995 pp. 335-369; Evans and Selina 2001; Hodgson 2002 p 319) takes evolution to be a generic process - Dennett calls it an algorithm (see also Blackmore 1995 pp. 48-60, 1999 p 11) - involving a population of replicators, carried by hosts or vehicles (which interact with the environment) and capable of reproducing themselves (via an inheritance mechanism) but subject to copying errors (variation) that affect their ability to survive and further reproduce (selection). Some critics argue that memes, and hence memetic evolution, are not empirically observable. Dennett (1995 p 346 emphasis suppressed) responds that, 'although the processes of cultural transmission of ideas are truly Darwinian phenomena, for various reasons they resist being captured in a Darwinian science, so that we will have to settle for the "merely philosophical" realisations we

\footnotetext{
${ }^{2}$ Dawkins derived the term 'meme' from the Greek root, 'mimeme', meaning 'imitated thing', shortened to rhyme with gene (Dawkins 1976 p 92).
} 
can glean from this, and leave science to tackle other projects'. I employ memetics here because these 'philosophical realisations' are fruitful in examining the issue I address.

Dawkins gave as examples of memes, 'tunes, ideas, catch-phrases, clothes fashions, ways of making pots or of building arches' (1976 p 92); more abstractly, Hodgson (2002 p 270) offers 'customs, routines, habits and ideas'. Formal definitions include, 'a salient (memorable) cultural item, something with enough design to be worth saving - or stealing or replicating' (Dennett $1995 \mathrm{p} \mathrm{143)}$ and 'information copied from person to person by imitation' (Blackmore 2001 p 225). The most common vehicles for memes are human brains, although other repositories such as books and computer drives are often considered to qualify (Blackmore 1999 p 5). McNamara (2011) refers to memes in brains as internal or i-memes and memes stored elsewhere as external or e-memes. The physical manifestation of a meme is often referred to as a phenotype (again by analogy with genetics), so that the concepts of joining things with threaded fasteners and the screwdriver are memes while actual screws and screwdrivers are phenotypes. It may be possible to infer the meme from its phenotype, so that, for example, a carpenter hitherto unfamiliar with cross-head screws may be able to work out their existence and functioning from an initial encounter with a cross-head screwdriver, but this will not always be the case. Some memeticists consider that where the idea behind a phenotype is readily apparent to potential imitators, such as the wheels on a waggon, the phenotype forms a vehicle for the meme (for example, Dennett 1995 p 348).

Although variation is often referred to as copying error, mutations are not necessarily blind or random: humans are highly prone to 'transform, invent, interpolate [and] censor' ideas (Dennett $1995 \mathrm{p} \mathrm{355).} \mathrm{Mutation,} \mathrm{in} \mathrm{short,} \mathrm{is} \mathrm{frequently} \mathrm{directed:} \mathrm{'memes} \mathrm{such} \mathrm{as} \mathrm{the} \mathrm{theory} \mathrm{of}$ relativity are not the cumulative product of millions of random (undirected) mutations of some original idea, but each brain in the chain of production added huge dollops of value added to the product in a non-random way' (private communication from Steven Pinker, cited by Dennett 1995 p 355).

A memeplex - analogous to a genome and abbreviated from 'coadapted meme complex' (Blackmore 1999 p 19), another concept and term devised by Dawkins - is a combination of compatible memes which enhances the survival prospects of its individual members, not because memes can 'cooperate' in any active sense, but because their effects are mutually beneficial; examples include a set of political or religious beliefs and subject expertise. A meme may be a member of any number of memeplexes, some overlapping and others embracing wider and wider groupings within the population of memes, or 'meme pool' (Blackmore 1999 p 41).

Memes can be passed on through generations of hosts (longitudinally), where host reproduction occurs, but are generally spread laterally, like a virus in an epidemic (Cavalli-Sforza and Feldman 1981). Memes and memeplexes evolve to better accommodate themselves to their environment, adapt further as their environment changes, and will die and be replaced by others if the newcomers have superior survival-promoting attributes or environmental change demands radically different attributes. The fate of a meme and the memeplexes of which it is a member will be determined by a complex range of factors deriving from the nature of human beings as imitators and selectors, the nature of memes themselves and their environment (Blackmore 1999 pp. 15-16). Ultimately the test is their fitness for the environments in which their struggle for survival and growth takes place. Many factors affecting a meme's performance in its environment are independent of its host's character; for example, a musical meme may succeed because it is attractive to audiences even though the musicians rendering it find it difficult or unappealing. Several competing memes may survive as long as they fit the 
environment equally well. Because a meme's prospects for survival and growth depend on its fitness for its environment, memetic evolution is progressive, not in the sense of working towards identified goals but, rather, in, without planning or foresight, better adapting to prevailing environments. Dawkins calls this 'climbing mount improbable (1996 book title), Dennett 'lifting in design space' (1995 p 326).

Memes attractive to their hosts for various reasons may nonetheless undermine their hosts' success and future prospects, including their propensity to reproduce, as in the behaviour that gave Dawkins the idea of memes in the first place. Complications can arise because of the social context in which memes and hosts exist. Popp (2007 p 104) invites us to consider the case of a member of a tribe having the insight that constructing a roof over their family's well protects their water supply from contamination and thereby improves their health and survival prospects: '[a]s others observe the roof and the consequently cleaner water, they may take up the practice of covering their wells.' He then introduces the suggestion that early adopters may attempt to keep the idea secret to promote their survival prospects against those of other families. The secrecy may extend to the meme itself, say by claiming that covers are employed for aesthetic reasons, or to instances of the phenotype, involving, perhaps, camouflaging well covers. We can add the possibility that interest groups seek to influence behaviour - carpenters exaggerate the sophistication of the set-up needed so that only professionals can construct it, say, or healers downplay the health benefits to maintain their market position. After a time, the group failing to adopt the innovation will be smaller than it would otherwise have been because their poorer health will have taken its toll on their reproductive power.

\section{Memes and Rules}

Imagine that the circumstances we have just discussed come to involve a regulatory authority perhaps the tribal elders - mandating well-covers for all members, even those who cannot grasp the rationale for them. Regulation is bound to change outcomes to some degree, but the character and extent of the change will depend on the regulator's skills, motivation, authority and behaviour. If an effective regulator fully understands the idea behind the innovation, resists spurious arguments from interest groups, implements the idea without irrelevant restrictions or embellishments, and requires its adoption by all families, the benefits for the tribe as a whole (against other tribes and nature generally) will be maximised, but they will be spread more widely.

Can the new rule be a meme? At first sight, the answer would appear to be negative: memes are ideas, spread by imitation, while rules are transmitted with some form of coercive backing. But the position is actually much more nuanced. Not surprisingly, the vocational discipline which has given most attention to the relationship between rules and memetics is the law itself. Approaches modelled more generally on evolutionary biology date from shortly after Darwin's own studies, including work by the distinguished jurist Oliver Wendell Holmes (Elliott 1985), and continue to the present (for one example, and a discussion of the recent literature, see Bork 2019). Within this stream of work, a number of studies draw explicitly on memetics (for a partial bibliography, see Goodenough 2006 note 7); several are of relevance to the subject of this paper, although the legal context does not exactly parallel accounting standardisation (or the case considered above), not least in that there is no 'prelapsarian' stage to be brought into consideration.

Fried (1999 p 307) examines 'rules of law, precedents and legal doctrines', essentially treating them as memes transmitted, via their judgements, between the brains of judges taken 
to fully understand them (with the advantage for the memeticist studying the process that court transcripts provide a 'fossil record') but without examining sources beyond judges or law originating outside the court system. Deakin (2002) proposes a much more wide-ranging theory of legal memetics, taking us closer to our topic. For Deakin, 'legal doctrine can be thought of as a particular mechanism of cultural transmission which works by coding information into conceptual form, thereby assisting its inter-temporal dissemination'; while,

[1] egal discourse possesses elements of autonomy and self-reference ... at the same time it is linked to wider social and biological processes through coevolution. Legal concepts are the equivalent of genetic replicators, with substantive rules or norms operating as interactors. This division mirrors a broader one in the social realm: memetic material (shared values, assumptions and heuristic categories) is embodied in the practices of institutions, understood as assemblages of rules, norms and conventions. Inheritance occurs through the replication of concepts over time. The unit of inheritance is the abstract concept or 'legal meme' which is carried forward at the point when one legal rule succeeds another (p 30, emphasis, note and cross-reference omitted).

Deakin rejects the argument that, though evolutionary forces may apply to judge-made law, they do not extend to legislation because "statutory rules are the product of conscious or planned intervention, while those of the common law derive from the "blind" interplay of litigation and adjudication.' He considers that '[t]his contrast is too strongly drawn. In both cases, conscious human agency is combined with elements of emergence' and 'legislation also encodes information' ( $\mathrm{p}$ 38). As we have already seen, mutation can be intellectually directed. Deakin, however, concedes that 'the legal order cannot be expected to respond directly to shifts in the social and economic environment. This implies a degree of "asynchronic" evolution' (p 37, emphasis supplied).

Goodenough (2006 p 997) points out that cultural replication ultimately rests on the imitation of action rather than ideas as such, proposing three modes of replication, law falling in the category of 'fully coded transmission ... through linguistic formulas [which] transmit abstracted behavioural information'. Schaper (2014) offers a concrete example of memetic analysis by showing how a complex legal structure (EU direct tax case law and normative texts) can be broken down into the memes it contains. Some studies examine memes originating outside the legal province, widely or narrowly defined: Ellis (2014) explores how the meme of voter fraud in the contemporary USA has come to be incorporated in the law while Greene (2016) explores how the meme 'substantive due process as contradiction' developed from strategic manoeuvring within legal argumentation rather than law-making as such.

Another vocational discipline that has given attention to the relation between memes and rules is theology. Van Wyk (2016) charts the development of theological conventions concerning inheritance in Old Babylonia Sippar, analysing them as a memeplex. Possibly the most dramatic case study of the meme-rule relationship is provided by Gottsch (2001 p 1), who plots the way in which ancient Near Eastern religious memes relating to hygiene and sexual behaviour came to be canonized, a 'process in which those exercising authority in a population select and exclude material in written texts, thus developing a non-contradictory religious canon', with the 'word canon ... [coming] to signify an act of setting standards'. He argues that the religiously mandated memes thus canonized improved the biological fitness and reproductive success of the sects subject to their influence and contrasts this with the cases of the Essenes and the, much later, American Shakers, of whom he tells us: 
This Christian sect adopted the fitness-minimizing theistic meme of celibacy.... The practicalities of this theistic meme meant that to gain new members the Shakers had to rely on adoptions and conversions. The number of Shaker societies grew in the early eighteenth century, but by the time of the Civil War the number of 'Believers' began to decline.... By the mid-twentieth century the membership had dwindled to forty. Soon thereafter the last male member died. The Shakers, unable to sustain their population, became extinct (p 32).

The theorising from law and theology sketched in this section, and in particular the ideas of Deakin (2002), Goodenough (2006) and Gottsch (2001), can be combined into the notion that, while rules, narrowly understood, are not memes as such, they embody a special kind of meme, encoding concepts and other ideas in the form of actions to be imitated to realise the consequences of those ideas. A standardising canon can be constructed by authorities selecting material emanating from a wider community, and its rules function as memes. The degree of synchronicity between the standardising canon at any given moment and the evolutionary pressures emerging from the changing environment for that canon will be influenced by the usual factors affecting the effectiveness and speed of evolutionary adaptation, but, because the memetic material in the canon is subject to directed mutation, particular importance attaches to the sensitivity of the authorities to environmental pressures and, specifically, to memetic material emerging from the wider community, the value of which will, in turn, depend on the vitality and sensitivity of that community in generating ideas. ${ }^{3}$

\section{Accounting Memes}

The ideas outlined in the previous section can be used to analyse the case of accounting standards. Accounting standards can be thought of as encoding the concepts and other ideas of accounting policies in the form of actions necessary to realise the consequences of those ideas, and forming a canon adopted by authorities selecting and excluding memetic material from a wider range available in the community. Most practitioners, most of the time, are likely to be following most standards because they possess the policies encoded in those standards as ideas, combined with a commitment to professional behaviours of certain sorts, rather than under an immediate threat of disciplinary penalties for failing to take the specified actions, in particular cases, and imposed by a monitor engaged in close observation. I turn to the question of how well the standardising canon is likely to function compared to previous arrangements in the next section; before I do, however, I need to say something about the general character of accounting memes.

An accounting meme pool includes not only the accounting policies found in textbooks and technical manuals and, in a regulated setting, embodied in standards, but also higher level doctrines such as prudence ${ }^{4}$ and going concern and the low level procedures necessary to implement policies, including basic bookkeeping techniques. The obvious phenotypes of accounting memes are instances of financial statements. In general, accounting procedures will be too complex, and embedded too far below the surface of financial statements, for memes to be discernible from this phenotype; even a statement of accounting policies

\footnotetext{
${ }^{3}$ This approach is extended to consider the case where the community previously employed memetic material generated by individual members without intervention by authorities in in a later section.

${ }^{4}$ The doctrine of prudence offers an interesting case study of relevance to the argument of this paper and I return to it later.
} 
generally yields too little information to enable someone unfamiliar with its memes to reproduce the application of the policies it contains. A type of accounting documentation to which relatively little attention is given in the academic literature is the set of well-prepared working papers signed off by management or auditor; this is the sort of phenotype, like the wheeled waggon, that can form a vehicle for its memes. Working papers may represent the only repository for low-level or newly-emerging e-memes.

Even in an unregulated setting, there will usually be what we can think of as a grand or overarching accounting memeplex, effectively, in that setting, the generally accepted accounting practice (GAAP) which Sanders, Hatfield and Moore identified in the USA in the mid1930s, well before even Grady's (1965) semi-authoritative project to document it:

There is, it is believed, a corpus of principles of accounting which are generally accepted. It is true that they are not 'written law'; they have not been codified; they must be sought in accounts and financial statements, in treatises, and in other evidences of professional opinion. It is true that they have not been adopted by vote of the profession. But that they have been accepted is evidenced by the common ways of thought and speech which make communication in accounting matters possible, by the generally uniform practice of all accountants when dealing with some situations, by the general agreement that, among all the possible ways of dealing with other situations, only a few can be used with propriety, by the restrictions of controversy in respect of propriety to a relatively small number of situations out of the innumerable number about which disagreement is possible (Sanders et al. 1938 p 5).

The grand memeplex can be characterised as a core surrounded by a less dense mantle of memes in transit inwards towards general acceptance or outwards, in the course of losing it, together with 'local' memeplexes, local, that is, to particular preparers, audit firms, or other contexts. Under standardisation the grand memeplex includes, of course, the memes embodied in the standardising canon and, if standardisation is functioning effectively, general acceptance of its memes flows from efforts of the standardising authority.

An accounting grand memeplex is likely to be highly organised, dense, cohesive and stable: there is a well-defined border between core and mantle, all the high-level memes an accountant in a given jurisdiction needs are in its grand memeplex, and the content of the memeplex changes only slowly. The grand memeplex, its vehicles and phenotypes will be strongly bound together by tight, integrated and interlocking relationships, both technically and socially. All financial statements use as high-level memes only those drawn from the grand memeplex; most cerebral vehicles (the brains of accountants involved in financial reporting, singly and in groups) contain, as a result of their hosts' professional training, more or less the whole of the grand memeplex (at least in the early stages of their hosts' careers); although low-level memes are not held in common, they are linked quite closely via their relationship to the grand memeplex and 'universal' accounting memes such as double-entry bookkeeping; and the local memeplex is likely to exhibit a high degree of stability because of the general requirement that the accounting policies of an entity should only be changed under exceptional circumstances (itself a consequence of a meme known as the doctrine of consistency). The character of accounting's grand memeplex can be contrasted with say, the world of classical music, where performers hold only a fraction of the wider memeplex cerebrally but may also hold memes from other genres; where performances (phenotypes) may depart from the score (meme) in matters such as tempo, expression and dynamics; and where scores can survive for long periods without performance without coming to be regarded as having left the memeplex. 
Variations in accounting memes come in various forms, including innovative procedures, adaptation of existing procedures to new or altered events and circumstances, abandonment of procedures, and changes in the way high-level procedures function as a consequence of innovation, adaptation or abandonment of related low-level procedures. Variations arise as a result of directed mutation, that is, the intellectual efforts of accountants: borrowing Pinker's words, each brain in the chain of production will add value in a non-random way. The accountants whose brains host memes and perform directed mutation are likely to be organised into close social groupings such as the finance division of individual companies or the technical staff of individual professional firms and these groupings are themselves part of wider institutional structures, such as professional bodies. An elaborate network will tend to engender strong technical and social ties and commitments to accounting's memeplexes. ${ }^{5} \mathrm{~A}$ combination of the character of memeplexes and the strength of hosts' technical and social commitment to them locates them within an exceptionally dense ecology in which variation at one point in the structure is heavily influenced by conditions elsewhere, limiting the scope for radical, destabilising or disharmonious change. Contrast this with, say, the world of marketing, where the most innovative campaign can be designed independently of other ideas within relevant memeplexes and implemented by a single team with little reference to other individuals or groups within the community.

Some individual accounting memes will have particular evolutionary advantages, such as being easy to memorise or easy or cheap to implement; some will, of course, be attractive to preparer hosts, not least for the impact they have on the presentation of financial performance. In a regulated setting, some memes may be particularly attractive to standard-setters, for example because they make for uncomplicated rule-making (including what are often called in the trade 'bright line' solutions) or are popular with political masters or influential interest groups. However, the nature of financial reporting as a service activity makes it likely that the most significant factors determining the environmental fitness of memes and memeplexes will derive from their suitability for the needs of the financial report users in that environment. A considerable weight of normative theory, and an extensive body of empirical findings, support the proposition that the primary use of corporate financial statements, and thus of the accounting memes bound up in them, is the making of investment decisions by, or on the recommendation of, financial analysts:

It is widely accepted in the academic literature that, despite its inherent limitations, financial reporting is among the most influential sources of information used by capital providers... Given that valuation (sometimes referred to as 'decision usefulness') is seen as the dominant role of contemporary financial reporting, it is unsurprising that financial statements have consistently been found to be very useful to professional investors when valuing a firm and its securities. This finding prevails across time and countries, regardless of investor type and the research methodology used (Cascino et al. 2016, note and reference omitted; for relevant reviews, see Cascino et al. 2013, 2014).

\footnotetext{
${ }^{5}$ Commitment specifically to accounting's procedures (and, thus, its memeplexes) is the subject of very little research but it seems likely that it is related to commitment to wider professional and organisational dimensions. Gendron et al. (2009 p 233) summarise the literature on this subject as follows:

Since the 1980s a number of studies have surveyed the relationship between professional accountants and their profession.... [P] rofessional commitment has been quite stable over time - ranging from 3.6 to 4.1 (out of 5).... [O]rganisational commitment has also been relatively stable over time, ranging from 3.7 to 4.3 (out of 5).
} 
The quality of enhancing investment decision-making may involve improving analysts' cash flow predictions directly, improving predictions of other dimensions of corporate performance contributing to returns (such as inventory management), or even improving discrimination in recognising non-financial dimensions of corporate performance that contribute to reliability of predictions (such as resilient managements that can respond effectively to unpredicted environmental impacts).

Analysts need not be hosts to accounting memes: their brains are not where memes are (necessarily) stored; they do not generate memetic variation; they do not directly select among memes. Rather, they are part of the environment with which hosts interact. Where alternative accounting memes are available to report on any category of transaction or event, analysts may find the outputs from particular memes attractive for a variety of reasons but they will not prosper unless, other things being equal, they tend to favour outputs from memes which enhance their investment decision-making. This will necessarily involve favouring investing in corporations that host memes leading to efficacious investment decision-making; even if some of these corporations have poor underlying performances, their use of such memes will better enable their security prices to be set appropriately. Given the stability in meme selection by hosts resulting from the doctrine of consistency, even if analysts are wholly unable to influence corporations' accounting, it will be sufficient over time for their investment decisions to lead to an expansion in the proportion of the corporate sector using memes generating their preferred outputs and a decline in, and potentially the elimination of, corporations retaining disfavoured memes as they struggle to obtain funding. In practice, of course, analysts do influence corporate hosts' meme selection. Even if analysts prefer meme outputs enhancing investment decision-making without understanding the causal connection, their choices will have the same effect.

As analysts' recommendations lead to disposals of investments in corporations employing decision-weakening memes, these corporations will come to be under-priced relative to their real resourcing and thus vulnerable to takeover by predators with decision-enhancing memes, which will then be applied to the purchased operations. Hosts that favour decision-enhancing memes will prosper, whether those making the selection favour them because they recognise their value in decision-making, because they understand that they are favoured by analysts, or for other reasons such as believing that choosing them is morally sound.

In a setting in which choice of accounting memes is restricted or eliminated altogether, quintessentially in a standardising regime in which standard-setters set out to adopt for their standards only one policy for any particular category of event, it may be thought that the powerful environmental forces deriving from analysts' decision-making needs will be more or less completely blunted: analysts will simply have to put up with what they are given. But we need to bear in mind three important considerations. First, unless a jurisdiction takes quite extraordinary steps not actually adopted in many, if any, western capitalist economies, corporations will always have the option of reporting alternative non-GAAP numbers to remedy any deficiency in the standardising canon, as perceived by preparers or users including analysts, up to and including delivering a full set of alternative financial statements alongside the official version. Secondly, the effect of analysts' recommendations in moving funds extends to movements between regimes and, further, corporations themselves can move between regimes; even if there is, as, indeed, there is, a standard-setter moving towards global domination, should its canon come to be perceived as defective, individual jurisdictions are likely to begin to withdraw from its coverage. Thirdly, analysts can also apply pressure directly to standard-setters. 


\section{Synchronicity of the Standardising Canon}

In this section I consider two separate but closely related questions: the synchronicity of the standardising canon with the evolutionary pressures emerging from its commercial and social environment - the issue addressed by Deakin (2002) - and the synchronicity of the standardising canon with the counterfactual of memes generated by the accounting community in a continuing unregulated setting - the central question of this paper.

It seems beyond question that the interventions of standard-setters will have some impact on the development of accounting. Equally, it also seems likely that, if these interventions drag the standardising canon too far in the direction of fitness reduction, the forces working to favour the selection of decision-enhancing memes discussed in the previous section will ultimately result in vehicles for the canon, including standard-setters and the more unresponsive practitioners, going the way of the American Shakers. Standard-setters' continued survival around the globe tells us something about the fitness of their canons. The first of the two questions posed at the beginning of this section is how effectively, especially in the medium and long term, has an accounting order driven by standardisation been able to respond to the evolutionary pressures emerging from its changing commercial and social environment? Following the approach set out in the section on 'Memes and Rules', we might examine the sensitivity and effectiveness of standard-setters in responding to environmental pressures, their engagement with memetic material emerging from the wider community, and the vitality and sensitivity of that community in developing such material.

But, because accounting underwent an unregulated era in the (relatively) recent past, we can recast the question. The survival and growth of accounting practice in the unregulated era argues that its emergent memes, tested individually in the crucible of evolutionary adaptation and coalescing into the grand memeplex, must have come to exhibit a high degree of environmental fitness. Certainly, the literature reviewed in the second section, whose beliefs about standardised accounting I am challenging, accepts this view of the prelapsarian past. Taking the unregulated memeplex to have been reasonably successful in minimising asynchronicity with commercial and social pressures, we can recast the question in the form Basu (2015) adopts, by comparing the performance of the standardising canon with that of a speculative, counterfactual, memeplex maintained by the community of practitioners in a continuing, unregulated, regime. With the question in this form, we need to focus, not on authorities' sensitivity to environmental forces, but rather on the relations between standardsetters and the wider community as a source of memetic material, both in the transitional phase between the unregulated and standardising eras and subsequently, together with the continuing vitality and sensitivity of the wider community in generating memetic material.

I suggest that the answer to the question in this form depends on the conditions of production of accounting standards: the skills, motivation, authority and behaviour of standard-setters; the relationship between the pre-regulation memeplex and the early canon; the relationship between practitioners' and standard-setters' intellectual forces and ideas - their intellection - after the establishment of standard-setting machinery; and the respective roles of coercion and imitation in practitioners' adoption of the behaviour encoded in accounting standards. Like the question we are addressing itself, the issues involved are not straightforwardly empirical. Judgements are required about conditions within the standard-setting machinery, and in the wider practitioner community, which are impossible or very difficult to observe and, in some cases, counterfactual. Further, the evidence must be judged against standards (in the generic sense) of what should and could be achieved. The issues are wide- 
ranging, deep and complex, with the possibility of different answers for different regimes impossible within the compass of a single paper, and perhaps ever, to go beyond the level of the philosophical realisations that Dennett encourages us to settle for. I can do no more than point to a limited range of evidence with respect to a small number of accounting regimes; here I address principally the UK, the USA and international accounting standards. ${ }^{6}$

A useful way into the issues is to focus on the degree of continuity in the conditions of production of accounting memes between the unregulated era and the standardising regime, and, hence, on the likely consequences of continuity for the functioning of the standardising canon. Perhaps the most visible evidence for broad continuity is the dominance of accounting practitioners at all stages in the emergence and operation of the machinery of standardisation dominance exercised both at the technical level and in the governance of the process, in many jurisdictions and internationally, and from the origins of standardisation to today. Zeff's (1972) path-breaking study of early standard-setting in five countries specifically identified this as one of the similarities he discerned across all the jurisdictions he studied.

In most regimes, standardisation, strictly defined, emerged, not directly from a prelapsarian era, but from a succession of increasingly rigorous, quasi-regulatory schemes, starting, perhaps, with exhortations to adopt best practice, defined in reality as a range of acceptable procedures, without any attempt at enforcement. Such pronouncements may achieve some regularisation by embarrassing the devious and educating the incompetent, but hardly discourage experimentation by the reflective practitioner. Thereafter, come schemes with a narrowing range of alternatives and increasingly effective enforcement. Continuities between these various stages, supported consensually in the pre-mandatory period, suggest that ideas emerging from the practitioner community have tended to survive into later periods and ultimately into the standardising era. There is evidence for such continuity in the UK between the prelapsarian and exhortatory periods, ${ }^{7}$ into initial attempts to impose standards, ${ }^{8}$ and beyond. ${ }^{9}$ In the USA, similarly, early series of pronouncements were non-mandatory until the introduction of the American Institute of Certified Public Accountants' Rule 203, requiring

\footnotetext{
${ }^{6}$ It is too early to assess with confidence the effect on this paper's argument of the March 2019 decision to adopt the Kingman recommendations to replace the UK's current regulatory arrangements for financial reporting (Department for Business, Energy \& Industrial Strategy 2019). Preliminary indications are that the greatest impact of the changes will be on auditing rather than accounting procedures, especially since it seems highly likely that listed entities will continue to use international accounting standards post-Brexit (Institute of Chartered Accountants in England and Wales 2018), and on governance rather than staffing (White 2019).

${ }^{7}$ The path to standardisation began with explicitly non-mandatory Recommendations on Accounting Principles. As Zeff (2009) shows, pronouncements were very carefully drawn from existing practice by elaborate arrangements designed to ensure a high degree of consensus among practitioners that the result represented best practice. The series was generally seen as successful in narrowing areas of difference, and thus, presumably, must have been accepted by practitioners as a progressive advance despite having emerged from institutionally-imposed arrangements.

${ }^{8}$ In its early days, the Accounting Standards Committee (ASC, then called The Accounting Standards Steering Committee) took over documents already under development within the structure responsible for the previous series of Recommendations (Sharp 1971) and early standards were generally widely supported, 'not perhaps as surprising as would appear at first sight when it is realised that the drafts are prepared by practical accountants and it is practical accountants who have, in the main, been asked to comment' (Sharp 1972 p 86).

${ }^{9}$ After several revisions in the structure of standard-setting, it remained possible for Bromwich (1985 p 31) to say that 'the ASC's Terms of Reference ... make it explicit that the aim is to narrow the areas of difference and variety in accounting practice by incorporating generally accepted "best" accounting practices into standards' and, somewhat more acidly, '[e]ven after its recent reorganisation ASC might still be thought to illustrate the profession's view of their proprietary rights concerning accounting' (Bromwich $1985 \mathrm{p} 31$ ). In the succinct formulation of Taylor and Turley (1986 p 66), 'the ASC has tended to induce standards from existing practices.'
} 
departures to be disclosed, in 1965 (Deegan and Unerman 2006 pp. 37-38), the focus in the early days being on 'a distillation of experience' (Tweedie 1996 p 19).

Turning to the contemporary scene, Botzem (2012) points out that, of the 12 strands of international regulation identified by the Financial Stability Board as necessary for wellfunctioning global financial systems, only accounting and auditing are the province of practitioner-run, and thus non-governmental, organisations. As he also points out, the extent to which accounting standard-setting is dominated by practitioners has been a regular source of criticism, which continues into the present. ${ }^{10}$ From the perspective of this paper, that accounting standards are set by accountants, and within a governance framework dominated by accountants, is surely a strongly positive feature arguing for continuity in accounting evolution. That standard-setting bodies often require, not only that members be accountants, but that they reach high levels of competence and experience, is also a positive feature. ${ }^{11}$

As well as providing standard-setters, the community of accounting practitioners has generally continued to have considerable influence on the development of standardisation. With the passage of time, constitutional arrangements have been revised to reduce that influence, for example, in the UK, professional body vetoes have long-since been abolished, but it remains substantial. It is worth quoting at length the words of David Solomons, one of the architects of the US Financial Accounting Standards Board (FASB) who was subsequently involved in standard-setting on both sides of the Atlantic (Solomons 1986, 1989). He begins by referring to the effective rejection of a draft UK standard by the membership of a professional accounting body, despite its having no formal standing on the matter:

In July 1977, an event occurred in London that brought home to accounting standard setters as never before the importance of making accounting standards acceptable to those who are subject to them. In that month, a resolution was passed by the members of the Institute of Chartered Accountants in England and Wales rejecting a mandatory system of current cost accounting... [T] he impact of the vote was just as great as the rejection of an FASB standard by the SEC would be in the United States.... [T] he 'voice of the people' had been heard, and the Accounting Standards Committee in Britain is never likely to forget it. Because of the different institutional arrangements for setting accounting standards in the United States, a precisely similar situation could not arise here. Yet the events of 1977 in Britain serve as a warning to accounting standard setters everywhere that they cannot lead unless the accounting and financial community is prepared to follow. The need for accounting standards to be acceptable has been recognised by members of the FASB in several speeches. It is also recognized in the elaborate and costly procedures, first introduced by the Accounting Principles Board and

\footnotetext{
${ }^{10}$ A recent report commissioned by the UK Labour Party complains that,

[t] he FRC [the UK Financial Reporting Council, the body currently responsible for standard-setting] board and operations are dominated by those with links to the big accountancy firms. Of the 15-member current main board, five are Big Four alumni .... The FRC Register [of Interests] shows that out of the 10 members of the FRC's codes and standards committee, four come from the Big Four, while five members of the 13-strong conduct committee have a Big Four background. Of the 44 names appearing on the Register, 18 are ICAEW [Institute of Chartered Accountants in England and Wales] members, one is a CIMA [Chartered Institute of Management Accountants] member, and two are ICAS [Institute of Chartered Accountants of Scotland] members (Sikka et al. 2018 p 32).

For earlier examples, see Burlaud and Colasse (2011), Porter (2005) and Walker (1987).

${ }^{11}$ For the International Accounting Standards Board, see Botzem (2012); for the Financial Accounting Standards Board, see Financial Accounting Standards Board (2013).
} 
since developed further by the FASB, to ensure due process for the business community

before a standard is finally imposed on it (Solomons 1986 pp 242-243).

In short, standard-setters recognise the need to achieve compliance as imitation rather than by coercion.

Examples of the routes by which influence is exerted today include the role of practitioners, individually and in groups, in generating memetic variation and bringing the results to the attention of standard-setters and others ${ }^{12}$ and the presence of accountants within groups exerting wider political pressure from preparers and users of financial statements. ${ }^{13}$

The evidence most frequently offered for a radical discontinuity following standardisation (including by Basu 2015) is the adoption, initially by the FASB and thereafter by other standard-setters including the International Accounting Standards Board (IASB), of a conceptual framework for standard-setting. This is a formal set of fundamental principles intended to inform the drafting of, though not replace, accounting standards, so that it can be thought of as forming a sort of supermemeplex, driving the directed variation within a lower memeplex, in this case accounting's grand memeplex including the standardising canon. A great deal of intellectual effort went into the formulation of the FASB framework and it has heavily influenced those of other standard-setters (Zeff 2016). In its early years, the FASB framework was vigorously critiqued by many academics as being largely no more than descriptive of contemporary practice (more evidence of continuity) and it did not seem that standard-setters were paying it much attention (see, for example, Hines 1989, 1991; Johnson 1985; Macve 1981). In recent years, however, standard-setters have come both to embrace the framework more enthusiastically in their standard-setting (Financial Accounting Standards Board 2013; International Accounting Standards Board 2013) and to resume developmental activity (Brouwer et al. 2015). Scholars (Baker 2017; Zeff 1999) have documented the continuities between the conceptual framework and the work of accounting theorists pre-dating it, the latter linking to contemporaneous accounting practice, suggesting that the conceptual framework is actually another influence for continuity.

The three aspects of the conceptual framework project offering most scope for a claim of radical discontinuity are: its adoption, as the objective of financial reporting, of the provision of information for investment decision-making rather than the more traditional formulation as information to inform judgements about stewardship; an alleged focus on the balance sheet rather than the income statement; and an alleged bias towards current value accounting (Tweedie 1996; Zeff 2016). If, as argued in the previous section, the survival of accounting memes depends to an important degree on their attractiveness to users of financial statements for the purpose of investment decision-making, the incorporation of such an objective in the supermemeplex would be simply an explicit recognition of already existing environmental conditions. In any event, in practice, the difference between the two formulations of the objective is much narrower than it might appear:

\footnotetext{
${ }^{12}$ In a different world, those discharging this role would include a wide representation of accounting academics but since the social scientific turn in accounting research they have largely abandoned the task of generating memetic material.

${ }^{13}$ Empirical evidence of practitioners' inputs to the process of standard-setting abound (see, for example, Allen et al. 2018; Jorissen et al. 2012; Reuter and Messner 2015); as in the case of the role of practitioners as standardsetters, academics often offer this evidence as criticism but, from the perspective of this article, it is a positive factor indicating the continued vibrancy of the community in generating memetic material and authorities' sensitivity to it. The position of users is taken up later in this section.
} 
The idea that stewardship is inconsistent with economic decisions was destroyed originally by the biblical parable of the talents.... Those users who wish to assess the stewardship of management do so in order that they make economic decisions [such as whether to hold or sell their investment in the enterprise or whether to re-appoint or replace the management].... It would be a singularly ineffective form of stewardship which did not lead to a decision of this type (Whittington $1991 \mathrm{p} \mathrm{33,} \mathrm{quoted} \mathrm{with}$ interpellation as shown by Higson 2003 p 75).

Technical staff working on the FASB conceptual framework found that advocates of stewardship were unable to offer convincing cases of information needed under that formulation that would not be called for under a decision-making objective (Zeff 2013 pp. 307-308). The close relation between the two formulations would account, indeed, for the survival of accounting memes in the pre-framework era.

On the second aspect, the FASB said explicitly that, in giving assets and liabilities conceptual primacy within the framework's system of financial statement element definitions, it was neither seeking to diminish the importance of revenue and expense nor to shift the focus away from earnings measurement (Storey and Storey 1998). Sir David Tweedie (1996), writing at the time that he was Chairman of the UK Accounting Standards Board (ASB, the successor to the ASC), explained that the FASB, and subsequently the ASB, saw the adoption of the balance sheet approach, not as supplanting matching, but rather as a development of a principle designed to eliminate certain practices already judged questionable by many practitioners.

On the third aspect, although the combination of the way the objective was formulated and the balance sheet approach was regarded by some as a plot to introduce current value accounting across the financial reporting system, this was routinely denied by the standardsetters involved and, although current values have been used subsequently in certain specific areas, no systematic roll-out has been attempted (Kirk 1988; Storey and Storey 1998).

Looking at the effect of the framework as a whole, Tweedie emphasises continuity rather than disruption (the UK version was in draft at the time but was subsequently adopted without major change):

The ASB's draft Statement of Principles is not a revolution .... Evolution is the key to the Board's approach... The draft Statement of Principles will result in a development of practice. The ASB wants to move at the pace with which the financial community feels comfortable (Tweedie 1996 p 33).

The Board's aim to pursue evolutionary rather than revolutionary change had been explicitly adopted by the Board (Tweedie $1996 \mathrm{p} \mathrm{22).} \mathrm{This} \mathrm{is} \mathrm{also} \mathrm{reflected} \mathrm{in} \mathrm{the} \mathrm{FASB's} \mathrm{version} \mathrm{of} \mathrm{the}$ framework, which explains that the Board 'intends future change to occur in the gradual, evolutionary way that has characterised past change' (Financial Accounting Standards Board 1984 paragraph 2).

The recent history of the doctrine of prudence offers a valuable case study in the issues discussed in this section: I focus here on aspects relating to international accounting standards. Well before the standardising era it had ceased to be acceptable to interpret prudence as justifying understatement of assets or overstatement of liabilities, judged against espoused accounting policies, and the first version of the international conceptual framework defined it in terms of caution in making judgements. The 2010 revision omitted prudence, as being incompatible with neutrality, and this proved controversial, including among a number of 
expert users; the concept was restored in the 2018 (current) version. Nobes (2015) points out that there is no evidence that the IASB adopted less prudent standards in the interim and much of the controversy actually concerned one class of items in one highly specialised sector (loan loss accounting for financial institutions), where the policy complained of (the incurred loss model), having actually been adopted somewhat before the 2010 framework revision, was subsequently replaced by a more prudent (expected loss) model. Arguably, then, although at the micro level we encounter a degree of disturbance, from a higher level we can observe the dense ecology of accounting (the need to fit new pronouncements into the overall structure slowing change) and continuity in intellection (broadly the same standard-setters and members of the wider community influencing standards on either side of the 2010 revision) yielding a stable equilibrium in the standardising canon, with a departure unacceptable to the audience influencing evolutionary success (users) swiftly reversed. ${ }^{14}$

In general then, and looking at matters in the round, we can observe a high degree of continuity, permeability and commonality - historically (from the pre-regulated era through quasi-regulation and into mature standardisation) and between the standardising regime, the rest of the accounting community, and a counterfactual continuation of an unregulated setting. There is a high degree of continuity in the training, socialisation, experience and commitments (including the commitment to compliance by imitation), and hence the intellection, of those generating memetic material, directing mutation and selection, and, under a standardising regime, encoding it in the canon, as well as in the memes passed from stage to stage on the path to a standardising canon, including via conceptual framework projects. The boundary between standard-setters and the rest of the community of practitioners remains highly permeable to both ideas and personnel, leading to a high degree of commonality across the whole community, and thus between standard-setters and those who would drive mutation in the counterfactual continuation of an unregulated regime, and the wider community retains its sensitivity to environmental needs and vitality as a source of memetic material. The technically and socially dense ecology of accounting memeplexes limits the scope for radical, destabilising or disharmonious change. A combination of the ecological density of memeplexes and continuity, permeability and commonality in the intellection directing their mutation makes for stability and congruence in that mutation as between its direction by individual practitioners and its mediation via a standardising canon.

This is not to suggest that there will be no differences between standardised accounting and what would have emerged in a continuing unregulated setting. There will (if only by chance) be some disparities between the policies adopted by standard-setters at any given moment and what would have emerged in an unregulated setting and, where those counterfactual alternatives would have proved as fit for the environment as the policies actually incorporated in the canon, they would have endured. The institutional structures of standardisation may also affect the corpus: for example, interest groups may be better able to influence a centralised system alternatively, standard-setters may be better able to resist pressure than individual accountants acting in an unregulated setting. On the other hand, convergence on stronger memes by the elimination of weaker ones is likely to be accelerated by the activities of a standard-setting body, including its own debates, its trialling of alternatives and their contact with a wider audience during the exposure period. This acceleration may also extend to the rate at which the

\footnotetext{
${ }^{14}$ Materials for the case study, covering the points made here, can be found in Camfferman (2015), European Financial Reporting Advisory Group (2013), Giner and Mora (2019), Nobes (2015) and Whittington (2008).
} 
canon as a whole evolves towards coherence and integration, especially after the introduction of a conceptual framework.

In reflecting on how different the developmental path might be overall we need to remember that the survival of accounting memes is likely to be predominantly a matter of their impact on investment decision-making and there is no reason to expect this factor to be affected by the introduction of standard-setting. Standard-setters have actively and explicitly accepted the importance of attending to the needs of investment decision-makers since the 1970s, if not before (Accounting Principles Board 1970 paragraph 73; Zeff 2013), and have formal procedures for consulting users of financial statements (in the USA, Financial Accounting Standards Board 2013 section III(c); internationally, International Financial Reporting Standards Foundation 2013 paragraphs 3.46-3.48). And, by and large, it would seem that accounting memeplexes do remain fit for their environments. Well into the twentyfirst century, after half a century of standard-setting in the USA and the UK, a sample drawn from North America, the UK and the rest of Europe, concluded that,

professional investors consider financial reporting data to be both relevant and faithfully represented overall, with an average rating of approximately five on the seven point scale (where seven indicates strong agreement with the statement that the information is relevant/faithfully represented) (Cascino et al. 2016 p 28).

So what is surely a demanding and sophisticated group of judges maintains its view that the evolution of accounting memes remains progressive, lifting the design of financial reporting to respond to contemporary challenges.

\section{Evidence for the Disruption of Evolution?}

The most significant empirical evidence offered by Basu (2015 pp. 247-248) for the disruptive outcome of accounting standardisation is drawn from work by Ely and Waymire (1999). ${ }^{15} \mathrm{He}$ reproduces a graph from their paper showing annual estimates of earnings value relevance for US stocks over time, divided into four periods, the first pre-dating regulation and the others covering successive regulators, of increasing effectiveness, culminating in the current body, the FASB. The graph displays very considerable volatility over all periods but Basu helpfully fits straight trend lines for the first and last periods, it would seem by eye since no explanation is provided and they do not appear in the original paper. In the first period the trend is steeply upwards and in the last almost as steeply downwards. As he puts it: 'before the SEC [ie before regulation], when accounting norms evolved spontaneously, value relevance increased. In contrast, during the conceptual-framework [ie final] period, value relevance declined precipitously' (Basu 2015 p 247).

Basu does not point out that Ely and Waymire went on to perform other tests and reached a rather more nuanced overall conclusion:

The evidence we report provides only limited support for the hypothesis that earnings relevance is materially higher [during any period after the first]. We find evidence of higher earnings relevance in the [second period] compared to the [first] .... However, this result is not robust .... We extend these tests .... The results ... are consistent with

\footnotetext{
${ }^{15}$ Basu offers other evidence but it is largely unsystematic, for example contrasting selected cases where unregulated accounting responded rapidly to particular problems with other cases where regulated accounting responded slowly to different problems.
} 
our returns results in that the incremental relevance of earnings does not exhibit significant increases [from period to period]. However, in tests examining the time series of the combined relevance of earnings and book value for equity valuation, we find a significant increase during the tenure of the FASB ... compared to [the previous period]. These findings are consistent with [previous evidence] showing an upward trend in combined relevance from the mid-1950s through the early 1990s [essentially from the middle of the second period to the final period]. For our yearly samples of NYSE stocks, these results appear attributable to the abnormally low combined relevance of earnings and book value during the [third period]; when combined relevance during the FASB era is compared against either the [first or second periods], differences are not significant at conventional levels (Ely and Waymire 1999 pp 314-315).

We should first note that there is a degree of scepticism within scholarly accounting about the legitimacy of drawing inferences about the functioning of corporate reporting from value relevance studies since "value-relevance tests ... [are] not backed up by theory and modelling of the underlying links between accounting, standard-setting and value' (Wyatt 2008 222, citing Holthausen and Watts' (2001) famous critique). Accepting value relevance as an appropriate measure for the purpose of this discussion, we can perhaps summarise Ely and Waymire's (1999) conclusions by saying that standard-setters struggled to maintain the quality of pre-regulation accounting but appear, broadly speaking, to have done so. What does this tell us about accounting evolution?

The first point to make is that even biological evolutionists do not expect to observe regular increases in the overall environmental fitness of a species, or even, indeed, the survival of the species at all. The case of the dodo does not prove, or even suggest, that its evolution ceased or became dysfunctional prior to its dying out: the dodo's problem was simply that changes in its environment overwhelmed its evolutionary capacity to adapt.

It is possible to identify a good many changes in the environment of financial reporting over the period covered by Ely and Waymire's (1999) data (1927 to 1993), a number of them quite plausibly likely to constitute major environmental challenges. As well as changes in corporate structures (for example, the development of multinational and transnational enterprises) and patterns of investment (for example the growth in institutional holding), with consequences for the specification of user-needs, there have been several major changes in the nature of commercial activity, giving rise to new and substantially altered transactions and events to be accounted for. Perhaps the most important member of the last category has been the rise, and increase in variety, of types of intangibles excluded from the balance sheet, which is regularly cited as the most important reason for a widening gap between market and balance sheet values, for example by Lev in numerous publications from 2001 to date (2018a, 2018b).

In the era before standardisation, some companies with significant intangibles were to be found and typically the unregulated accounting of the day was extremely cautious about incorporating them in the balance sheet (Basu and Waymire 2008). Accounting for intangibles has evolved since the pre-standardisation era (Boennen and Glaum 2014; d'Arcy and Tarca 2018; Dedman et al. 2009), including disclosure of expenditure on internally-generated intangibles. Since pre-standardisation accounting was reluctant to capitalise even relatively small amounts of intangibles on account of the unreliability of their measurement (O'Hogartaigh 2009; Yang 1927 p 19), rather than merely because they were too small to worry about, it must remain an open question whether a consensus going substantially further would have emerged from unregulated accounting. 


\section{Conclusion}

This paper employs memetic theory to analyse the argument that accounting standardisation disrupts, and eventually overwhelms, the progressive evolution of accounting by admitting a force unresponsive to the discipline's environment. I suggest that in an unregulated setting accounting procedures, including accounting policies, constitute memes in the classic sense and will survive, not on account of their attractiveness to their hosts, but according to their fitness for their environment. I argue that the environmental fitness of accounting memes, and the memeplexes into which they coalesce, will be predominantly a matter of their suitability for the needs of financial analysts in their work of investment decision-making. In a standardising regime, the standardising canon embodies a special kind of accounting meme, encoding ideas in the form of actions to be imitated to realise the consequences of those ideas. The evolutionary pressures emerging from accounting's commercial and social environment and the standardising canon develop in tandem, although they may advance asynchronously.

Because the memetic material in the standardising canon is subject to directed mutation adaptation driven by intellectual forces - the degree of asynchronicity between evolutionary pressures and the canon will be influenced by the sensitivity of the standardising authorities to those pressures, either directly or via memetic material emerging from a wider community which itself remains sensitive to those pressures. If we accept the central tenet of memetic theory, which is also the assumption underlying the argument challenged in this paper, namely that the memes freely emerging and adapting in the era before regulation were highly responsive to evolutionary pressures, we can analyse the likely responsiveness of the standardising canon by examining its relationship to a counterfactual continuation of the pre-regulated regime. By recasting the question in this way we are directly addressing the argument that standardisation disrupts evolution - the argument it is the purpose of this paper to challenge. The degree of synchronicity is ultimately an empirical question but a highly elusive one and I argue that we should follow Dennett's recommendation that we settle for the philosophical realisations we can glean from memetic theory.

I argue that three factors are of central importance in addressing the question. First, accounting memeplexes function within an exceptionally dense ecology, technically and socially, and this limits the scope for radical, destabilising or disharmonious change. Secondly, there has been a high degree of continuity, permeability and commonality in the intellection driving memetic development (including, in the standardising era, encoding it in the canon), both historically, from wholly unregulated accounting to full standardisation, and between the standardising authorities and those who would drive development in the counterfactual continuation of unregulated accounting; put in the simplest terms, the practitioner community has retained its significance and vitality in contributing to evolutionary adaptation and the same sort of thinking has permeated the design of accounting procedures wherever it has taken place. Finally, the principal determinant of successful adaptation did not change on the transition to standardisation: environmental fitness remains a matter of suitability for investment decision-taking; standard-setters have taken considerable care to address the needs of analysts; analysts have, by and large, confirmed that these efforts have been successful; and the canon and its usefulness have survived. ${ }^{16}$

\footnotetext{
${ }^{16}$ Survival in itself might be a consequence of memetic adaptation to changed requirements for environmental fitness coming about on the adoption of standardisation, for example, attractiveness to regulators or their political masters. However, its combination with the factors discussed here argues against this interpretation.
} 
As a consequence of these factors, we can reasonably conclude that accounting standardisation has not disrupted the progressive development of the discipline in response to the commercial and social environmental forces it faces - a development that is progressive in Dennett's non-teleological sense of 'lifting in design space' (1995 p 326). I consider some empirical evidence that has been offered for the disruptive hypothesis and suggest an alternative interpretation consistent with my argument.

As a postscript I want to say something about the role of accounting standards. It might be thought that the main conclusion of this paper suggests that there is actually no need for standards but I want to emphasise that, to the contrary, and as I point out in the paper, there is an important role for standards within a memetic theorisation of accounting. That role is to limit the scope for devious and incompetent accounting by individual practitioners and to accelerate convergence on better-adapted memetic material and a coherent and integrated canon - that is, to further reduce the degree of asynchronicity between a changing environment, especially a rapidly changing one, and the memetic material generated by accounting practitioners in response.

Acknowledgements The author is very grateful for the helpful comments of the anonymous reviewers.

\section{Compliance with Ethical Standards}

Conflict of Interest The author states that there is no conflict of interest.

Open Access This article is licensed under a Creative Commons Attribution 4.0 International License, which permits use, sharing, adaptation, distribution and reproduction in any medium or format, as long as you give appropriate credit to the original author(s) and the source, provide a link to the Creative Commons licence, and indicate if changes were made. The images or other third party material in this article are included in the article's Creative Commons licence, unless indicated otherwise in a credit line to the material. If material is not included in the article's Creative Commons licence and your intended use is not permitted by statutory regulation or exceeds the permitted use, you will need to obtain permission directly from the copyright holder. To view a copy of this licence, visit http://creativecommons.org/licenses/by/4.0/.

\section{References}

Board, Accounting Principles. 1970. Statement on accounting principles no. 4: Basic concepts and accounting principles underlying financial statements of business enterprises. New York: American Institute of Certified Public Accountants.

Allen, A., K. Ramanna, and S. Roychowdhury. 2018. Auditor lobbying on accounting standards. Journal of Law, Finance, and Accounting 3 (2): 291-331.

Baker, C.R. 2017. The influence of accounting theory on the FASB conceptual framework. Accounting Historians Journal 44 (2): 109-124.

Basu, S., M. Kirk, and G.B. Waymire. 2009. Memory, transaction records and The Wealth of Nations. Accounting, Organizations and Society 34 (8): 895-917.

Basu, S., and G.B. Waymire. 2019. Historical cost and conservatism are joint adaptations that help to identify opportunity cost. Accounting, Economics and Law: A Convivium 9 (1): 1-13.

Basu, S. 2015. Is there a scientific basis for accounting? Implications for practice, research, and education. Journal of International Accounting Research 14 (2): 235-265.

Basu, S., and G.B. Waymire. 2008. Has the importance of intangibles really grown? And if so, why? Accounting and Business Research 38 (3): 171-190.

Baxter, W.T. 1953. Recommendations on accounting theory. The Accountant 10 October: 405-410.

Baxter, W.T. 1981. Accounting standards: Boon or curse? Accounting and Business Research 12 (45): 3-10. 
Baxter, W.T. 1982. Accounting standards: Boon or curse? A reply. Accounting and Business Research 13 (49): 63-64.

Beams, F.A. 1969. Indications of pragmatism in accounting thought. Accounting Review 44 (2): 382-388.

Benston, G.J., M. Bromwich, R.E. Litan, and A. Wagenhofer. 2006. Worldwide financial reporting: The development and future of accounting standards. Oxford: Oxford University Press.

Blackmore, S. 1999. The meme machine. Oxford: Oxford University Press.

Blackmore, S. 2001. Evolution and memes: The human brain as a selective imitation device. Cybernetics and Systems 32 (1): 225-255.

Boennen, S., and M. Glaum. 2014. Goodwill accounting: A review of the literaure. Working Paper: JustusLiebig-Universität Giessen, Giessen, Germany.

Bork, K.S. 2019. An evolutionary theory of administrative law. SMU Law Review 72 (1): 81-138.

Botzem, S. 2012. The politics of accounting regulation: Organising transnational standard-setting in financial reporting. Cheltenham, UK: Edward Elgar.

Braun, E. 2019. The ecological rationality of historical costs and conservatism. Accounting, Economics and Law: A Convivium 9 (1): 1-30.

Bromwich, M. 1985. The economics of accounting standard setting. London: Prentice-Hall/Institute of Chartered Accountants in England and Wales.

Brouwer, A., M. Hoogendoorn, and E. Naarding. 2015. Will the changes proposed to the conceptual framework's definitions and recognition criteria provide a better basis for IASB standard setting? Accounting and Business Research 45 (5): 547-571.

Burlaud, A., and B. Colasse. 2011. International accounting standardisation: Is politics back? Accounting in Europe 8 (1): 23-48.

Camfferman, K. 2015. The emergence of the 'incurred-loss' model for credit losses in IAS39. Accounting in Europe 12 (1): 1-35.

Cascino, S., M. Clatworthy, B. García Osma, J. Gassen, S. Imam, and T. Jeanjean. 2014. Who uses financial reports and for what purpose? Evidence from capital providers. Accounting in Europe 11 (2): 185-209.

Cascino, S., M. Clatworthy, B. García Osma, J. Gassen, S. Imam, and T. Jeanjean. 2016. Professional investors and the decision usefulness of financial reporting. Brussels and Edinburgh: European Financial Reporting Advisory Group and Institute of Chartered Accountants of Scotland.

Cascino, S., M. Clatworthy, B. García Osma, J. Gassen, S. Imam, and T. Jeanjean. 2013. The use of information by capital providers: Academic literature review. Brussels and Edinburgh: European Financial Reporting Advisory Group and Institute of Chartered Accountants of Scotland.

Cavalli-Sforza, L.L., and M.W. Feldman. 1981. Cultural transmission and evolution: a quantitative approach. Princeton, New Jersey: Princeton University Press.

d'Arcy, A., and A. Tarca. 2018. Reviewing IFRS goodwill accounting research: Implementation effects and cross-country differences. The International Journal of Accounting 53 (3): 203-226.

Dawkins, R. 1976. The selfish gene. Oxford: Oxford University Press.

Dawkins, R. 1996. Climbing mount improbable. London: Penguin.

Deakin, S. 2002. Evolution for our time: A theory of legal memetics. Current Legal Problems 55 (1): 1-42.

Dedman, E., S. Mouselli, Y. Shen, and A.W. Stark. 2009. Accounting, intangible assets, stock market activity, and measurement and disclosure policy: Views from the UK. Abacus 45 (3): 312-341.

Deegan, C., and J. Unerman. 2006. Financial accounting theory. Maidenhead, Berkshire: McGraw Hill.

Deinzer, H.T. 1965. Development of accounting thought. New York: Holt, Rinehart and Winston.

Deinzer, H.T. 1966. Explanation strains in financial accounting. Accounting Review 41 (1): 21-31.

Dennett, D. 1995. Evolution and the meaning of life. New York: Simon and Schuster.

Department for Business, Energy \& Industrial Strategy. 2019. Press release: Audit regime in the UK to be transformed with new regulator. London: DBEIS.

Devine, C.T. 1966. Review of Deinzer, H.T., Development of accounting thought. New York: Holt, Rinehart and Winston, 1965. Accounting Review 41 (1): 189-192.

Devine, C.T. 1985. Essays in accounting theory: volume v. np: American Accounting Association.

Dopuch, N. 1962. Metaphysics of pragmatism and accountancy. Accounting Review 37 (2): 251-262.

Elliott, D.E. 1985. The evolutionary tradition in jurisprudence. Columbia Law Review 85 (1): 38-94.

Ellis, A.R. 2014. The meme of voter fraud. Catholic University Law Review 63 (4): 879-916.

Ely, K., and G.B. Waymire. 1999. Accounting standard-setting and earning relevance: Longitudinal evidence from NYSE common stocks, 1927-93. Journal of Accounting Reseach 37 (2): 293-317. 
European Financial Reporting Advisory Group. 2013. Getting a better framework: Prudence. Brussels: EFRAG. Evans, D., and H. Selina. 2001. Introducing evolution. Royston: Icon Books.

Financial Accounting Standards Board. 1984. Statement of financial accounting concepts no. In 5: Recognition and measurement in financial statements of business enterprises. Stamford, Connecticut: FASB.

Board, Financial Accounting Standards. 2013. Rules of procedure. Norwalk, Connecticut: FASB.

Fried, M.S. 1999. The evolution of legal concepts: The memetic perspective. Jurimetrics 39 (3): 291-316.

Gendron, Y., R. Suddaby, and S.Q. Qu. 2009. Professional-organisational commitment: A study of Canadian professional accountants. Australian Accounting Review 19 (3): 231-248.

Giner, B., and A. Mora. 2019. Bank loan loss accounting and its contracting effects: The new expected loss models. Accounting and Business Research 49 (6): 726-752.

Goodenough, O.R. 2006. Cultural replication theory and law: Proximate mechanisms make a difference. Vermont Law Review 30 (4): 989-1004.

Gottsch, J.D. 2001. Mutation, selection and vertical transmission of theistic memes in religious canons. Journal of Memetics 5 (1): 1-32.

Grady, P. 1965. Inventory of generally accepted accounting principles for business enterprises. New York: American Institute of Certified Public Accountants.

Greene, J. 2016. The meming of substantive due process. Constitutional Commentary 31 (2): 253-294.

Higson, Andrew. 2003. Corporate financial reporting: Theory and practice. London: Sage.

Hines, R.D. 1989. Financial accounting knowledge, conceptual framework projects and the social construction of the accounting profession. Accounting, Auditing \& Accountability Journal 2 (2): 72-92.

Hines, R.D. 1991. The FASB's conceptual framework, financial accounting and the maintenance of the social world. Accounting, Organizations and Society 16 (4): 313-332.

Hodgson, G. 2002. Darwinism in economics: From analogy to ontology. Journal of Evolutionary Economics 12 (3): 259-281.

Holthausen, R.W., and R.L. Watts. 2001. The relevance of the value-relevance literature for financial accounting standard setting. Journal of Accounting and Economics 31 (1-3): 3-75.

Institute of Chartered Accountants in England and Wales. 2018. Representation 36/18: Comments on the future endorsement of IFRS post-Brexit. London: ICAEW.

International Accounting Standards Board. 2013. Press release: IASB publishes discussion paper on the conceptual framework, 18 July. London: IASB.

International Financial Reporting Standards Foundation. 2013. Due process handbook. London: IFRSF.

Jamal, K., and S. Sunder. 2014. Monopoly versus competition in setting accounting standards. Abacus 50 (4): 369-385.

Ji, X., and W. Lu. 2013. The evolution of bookkeeping methods in China: Analysis of developments during the twentieth century. Accounting History 18 (3): 317-341.

Johnson, L.T. 1985. The conceptual framework: A retrospective. The Chartered Accountant in Australia September: 23-25.

Jorissen, A., N. Lybaert, R. Orens, and L. Van Der Tas. 2012. Formal participation in the IASB's due process of standard setting: A multi-issue/multi-period analysis. European Accounting Review 21 (4): 693-729.

Kirk, D.J. 1988. Looking back at the FASB: The education of a standard-setter. Accounting Horizons 2 (1): 8-17.

Lev, B. 2001. Intangibles: Management, measurement and reporting. Washington, DC: Brookings Institution Press.

Lev, B. 2018a. The deteriorating usefulness of financial report information and how to reverse it. Accounting and Business Research 48 (5): 465-493.

Lev, B. 2018b. Ending the accounting-for-intangibles status quo. European Accounting Review 28 (4): $713-736$.

Littleton, A.C. 1953. Structure of accounting theory. Np: American Accounting Association.

Littleton, A.C. 1962. Review of Moonitz, M., The basic postulates of accounting. New York: American institute of certified public accountants 1961. Accounting Review 37 (3): 602-605.

Macve, R. 1981. A conceptual framework for financial accounting and reporting: The possibilities for an agreed structure. London: Institute of Chartered Accountants in England and Wales.

McNamara, A. 2011. Can we measure memes? Frontiers in Evolutionary Neuroscience 3 (1): 1-7.

Moonitz, M. 1961. The basic postulates of accounting. New York: American Institute of Certified Public Accountants.

Myddelton, D.R. 2004. Unshackling accountants. London: Institute of Economic Affairs.

Nobes, C.W. 2015. IFRS ten years on: Has the IASB imposed extensive use of fair value, has the EU learnt to love IFRS, and does the use of fair value make IFRS illegal in the EU? Accounting in Europe 12 (2): 153170. 
O’Hogartaigh, C. 2009. Financial accounting practice. In The Routledge companion to accounting history, ed. S.P. Walker and J.R. Edwards, 162-188. London: Routledge.

Paton, W.A. 1922. Accounting theory. New York: The Ronald Press Company.

Paton, W.A., and A.C. Littleton. 1940. An introduction to corporate accounting standards. Sarasota, Florida: American Accounting Association.

Popp, J.A. 2007. Evolution's first philosopher: John Dewey and the continuity of nature. Albany, New York: State University of New York Press.

Porter, T. 2005. Private authority, technical authority and the globalisation of accounting standards. Business and Politics 7 (3): 1-30.

Reuter, M., and M. Messner. 2015. Lobbying on the integrated reporting framework: An analysis of comment letters to the 2011 discussion paper of the IIRC. Accounting, Auditing \& Accountability Journal 28 (3): $365-$ 402.

Sanders, T.H., H.R. Hatfield, and U. Moore. 1938. A statement of accounting principles. New York: American Institute of Accountants.

Schaper, M.G.H. 2014. A computational legal analysis of acte clair rules of EU law in the field of direct taxes. World Tax Journal 6 (1): 77-108.

Sharp, K. 1971. Accounting standards after twelve months. Accountancy May: 239-245.

Sharp, K. 1972. Accounting standards after twelve months - addendum: A note on the further development of accounting standards 1971/72. In Forging accounting principles in five countries: a history and an analysis of trends, S. A. Zeff, 85-90. Champaign, Illinois: Stipes.

Sikka, P., J. Christensen, C. Cooper, D.G. Driver, T. Hadden, C. Haslam, J. Haslam, et al. 2018. Reforming the auditing industry. London: Labour Party.

Solomons, D. 1986. Making accounting policy: The quest for credibility in financial reporting. New York: Oxford University Press.

Solomons, D. 1989. Guidelines for financial reporting standards. London: Institute of Chartered Accountants in England and Wales.

Storey, R.K., and S. Storey. 1998. The framework of financial accounting concepts and standards. Norwalk, Connecticut: Financial Accounting Standards Board.

Sunder, S. 2011. IFRS monopoly: The Pied Piper of financial reporting. Accounting and Business Research 41(3):291-306.

Taylor, P., and S. Turley. 1986. The regulation of accounting. Oxford: Basil Blackwell.

Tweedie, D.P. 1996. Regulating change - the role of the conceptual statement in standard-setting. In Accounting and performance measurement: Issues in the private and public sectors, ed. I. Lapsley and F. Mitchell, 1834. London: Paul Chapman Publishing.

Van Wyk, S.J. 2016. The survival fitness of memes in the inheritance divisions from old Babylonia Sippar. Journal for Semitics 25 (1): 318-346.

Walker, M. 2010. Accounting for varieties of capitalism: The case against a single set of global accounting standards. British Accounting Review 42 (3): 137-152.

Walker, R.G. 1987. Australia's ASRB: A case study of political activity and regulatory capture. Accounting and Business Research 17 (67): 269-286.

West, B. 2003. Professionalism and accounting rules. London: Routledge.

White, S. 2019. FRC to be disbanded as government green lights new audit regulator. Accountancy Daily. https://www.accountancydaily.co.uk/frc-to-be-disbanded-as-governmentgreen-lights-new-audit-regulator. Accessed 12 March 2019.

Whittington, G. 1991. Good stewardship and the ASB's objectives. Accountancy November 33.

Whittington, G. 2008. Fair value and the IASB/FASB conceptual framework: An alternative view. Abacus 44 (2): 139-168.

Williams, P.F. 2001. Review of C.T. Devine, Essays in accounting theory: a capstone. New York: Garland 1999. Accounting Review 76 (4): 694-696.

Wyatt, A. 2008. What financial and non-financial information on intangibles is value-relevant? A review of the evidence. Accounting and Business Research 38 (3): 217-256.

Yang, J.M. 1927. Goodwill and other intangibles: Their treatment in accounts. New York: Ronald Press.

Zeff, S.A. 1972. Forging accounting principles in five countries: A history and an analysis of trends. Champaign, Illinois: Stipes. 
Zeff, S.A. 2016. The Trueblood study group on the objectives of financial statements (1971-73): A historical study. Journal of Accounting and Public Policy 35 (2): 134-161.

Zeff, S.A. 1999. The evolution of the conceptual framework for business enterprises in the United States. Accounting Historians Journal 26 (2): 89-131.

Zeff, S.A. 2009. Principles before standards: The ICAEW's 'N series' of recommendations on accounting principles, 1942-1969. London: Institute of Chartered Accountants in England and Wales.

Zeff, S.A. 2013. The objectives of financial reporting: A historical survey and analysis. Accounting and Business Research 43 (4): 262-327.

Publisher's Note Springer Nature remains neutral with regard to jurisdictional claims in published maps and institutional affiliations.

Brian Rutherford held a chair in Accounting at the University of Kent from 1988 to 2009 and is now Emeritus Professor. He served the University as Head of the Department of Accounting, Director of Kent Business School and Dean of the Faculty of Social Sciences. He graduated from the University of Exeter with a degree in Economics, holds a $\mathrm{PhD}$ in Accounting, and qualified as an accountant while working in the international headquarters of a major multinational. He has worked in industry and for an accounting standard-setting body, the International Accounting Standards Committee. He has more than 100 publications, including ten books, to his name. 